\title{
Successful aging defined by health-related quality of life and its determinants in community- dwelling elders
}

\author{
Chia-Ing Li $i^{1,2}$, Chih-Hsueh Lin 2,3, Wen-Yuan Lin ${ }^{2,3}$, Chiu-Shong Liü ${ }^{2,3}$, Chin-Kai Chang ${ }^{2,4}$, Nai-Hsin Meng ${ }^{2,4}$, \\ Yi-Dar Lee ${ }^{5,6}$, Tsai-Chung Li $i^{7,8,9^{*}}$ and Cheng-Chieh Lin ${ }^{2,3,8,9^{*}}$
}

\begin{abstract}
Background: Successful aging in old age is important. However, the determinants of successful aging vary across populations due to cultural differences, and only a limited number of studies have addressed these determinants in Taiwan population. This study aimed to evaluate successful aging via better physical and mental functions as well as to explore associated determinants in an elderly Taiwan population that had no impaired cognitive function.

Methods: A community-based cross-sectional survey was conducted in January 2009 in Taichung, Taiwan. A total of 903 elderly persons ( $\geq 65$ years) without impaired cognitive function were enrolled. Those with physical and mental component scores in the top tertile of the Short-Form 36 were considered to be aging successfully. All participants completed a structured questionnaire and the comprehensive geriatric assessment measurements of the five components of frailty defined by Fried et al. Crude and adjusted odds ratios (ORs) with 95\% confidence intervals (Cls) were calculated to evaluate the relationship between associated factors and successful aging using logistic regression analysis.

Results: The prevalence of successful aging was $10.4 \%$ in elders. A higher proportion of successful aging was found in non-frail (16.9\%) and pre-frail elders (7.2\%) than in frail elders (0.9\%). Multivariate logistic regression showed pre-frail elders to be associated with lower prevalence of successful aging relative to non-frail elders (OR: 0.45 ; $95 \%$ Cl: $0.24-0.84$ ). Relative to those aged $\leq 70$ years, elders aged 71-75 years were associated with a lower prevalence of successful aging (OR: 0.27; 95\% Cl: 0.13-0.58). Successful aging was also more likely among those able to visit relatives and friends (OR: 3.86, 95\% Cl: 1.09-13.61) and among those without a history of falling (OR: 4.95; 95\% Cl: 1.79-13.74), pain (OR: 4.04; 95\% Cl: 2.18-7.50), or sleep disorders (OR: 2.36; 95\% Cl: 1.30-4.27).
\end{abstract}

Conclusion: Successful aging was associated with age, frail status, chronic health-related problems and psychosocial support. However, whether or not these associations are causal requires further exploration.

Keywords: Aged, Successful aging, Quality of life

\section{Background}

The proportion of the elderly population aged $\geq 65$ years has continued to dramatically increase worldwide from $8 \%$ in 1950 to $11 \%$ in 2009 [1]. A similar tendency has occurred in Taiwan, as the number of elderly people increased by approximately $2 \%$ each year throughout the 1990s. The proportion of elderly Taiwanese is projected

\footnotetext{
*Correspondence: tcli@mail.cmu.edu.tw; cclin@mail.cmuh.org.tw

${ }^{7}$ Graduate Institute of Biostatistics, College of Management, China Medical

University, Taichung, Taiwan

${ }^{2}$ School of Medicine, College of Medicine, China Medical University,

Taichung, Taiwan

Full list of author information is available at the end of the article
}

to further increase almost threefold from $10 \%$ in 2009 to $36 \%$ by 2050 . Because the aging process is associated with increased susceptibility to chronic conditions, disabilities, psychosocial problems and comorbidities [2,3], it is important that this aging population is able to enter late stages of life in relatively good health.

An extensive review of 28 quantitative studies reported that there are several methods to operationally define and measure successful aging [4]. The prevalence and definitions of successful aging were found to vary among studies [4]. As the number of included domains increased, definitions of successful aging tended to become more complex

\section{Biomed Central}

(c) 2014 Li et al.; licensee BioMed Central Ltd. This is an Open Access article distributed under the terms of the Creative Commons Attribution License (http://creativecommons.org/licenses/by/2.0), which permits unrestricted use, distribution, and reproduction in any medium, provided the original work is properly credited. 
[5]; there was, however, a consensus regarding the multidimensional nature of successful aging [4-6]. The Study of Health Assessment and Risk in Ethnic groups also reported a cross-national variation in the prevalence of successful aging among 14 European countries. The authors suggested that self-reported health measures may be the most appropriate measures for comparing cross-national differences to avoid diagnostic differences across countries [7]. Multidimensional, standardized, and self-rated instruments are more practical and are more easily comparable among different countries and populations.

The Short Form-36 (SF-36) is a multidimensional scale and a well-established instrument that measures health concepts and self-reported health-related quality of life [8]. Using SF-36 to define successful aging is acceptable because it represents overall health status in two key measures-the physical component summary (PCS) and the mental component summary (MCS) scores. These two scores reflect the status of physical, mental, and social well-being that are generally used to define health status [9]. The aim of this study was to explore the prevalence of successful aging, as gauged by SF-36, as well as to identify determinants of successful aging among communitydwelling elders.

\section{Methods}

\section{Population and participants}

We conducted a population-based cross-sectional study in June 2009 with a target population of all residents aged $\geq 65$ years residing in eight administrative neighborhoods of Taichung, Taiwan. Taichung is located in westcentral Taiwan and has a population of just over one million people, making it the third largest city on the island; its area spans $163.4 \mathrm{~km}^{2}$, and the population density is $6,249 / \mathrm{km}^{2}$ (2009). There were 3,997 elderly residents in these eight administrative neighborhoods of Taichung, accounting for $4.5 \%$ of the population. Data for this study were obtained from individuals' records compiled by the Bureau of Households; details of this study's sampling method are described elsewhere [10]. This research was approved by the Human Research Committee of China Medical University Hospital, and written informed consent was obtained from each participant. A total of 1,347 elderly residents of Taichung participated in this study, yielding an overall response rate of $49.0 \%$. Among these participants, 256 elderly residents completed only the first stage of the screening test for the frailty assessment and did not submit responses to the SF36 questionnaire. A total of 903 elders were included in the final data analysis after excluding those diagnosed with dementia $(n=18)$, those lacking Mini-Mental State Examination (MMSE) information $(\mathrm{n}=5)$, those with MMSE scores less than 14 points $(n=8)$, those who had incomplete frailty-related components $(\mathrm{n}=87)$, and those with incomplete SF-36 information $(\mathrm{n}=70)$.

\section{Measurements \\ Successful aging}

Measurements from the SF-36 instrument were applied to identify whether the elderly residents of Taichung were aging successfully. The SF-36 is a short questionnaire with 36 items that measures the following eight multi-item variables: physical functioning (PF, 10 items), social functioning (SF, 2 items), role limitations due to physical problems (RP, 4 items), role limitations due to emotional problems (RE, 3 items), mental health ( $M H, 5$ items), vitality (VT, 4 items), pain (BP, 2 items), and general perception of health (GH, 5 items). The scores for each variable item were coded, summed, and transformed into a score ranging from 0 (worst measured health state) to 100 (best measured health state). The SF-36 PCS and MCS scales were derived from the standard SF-36 scoring algorithms. Elders with both PCS and MCS in the highest tertile, indicating the best states of physical and mental health, were considered to be successfully aging. The cutoff scores of the top tertile were 53.00 for the PCS and 59.28 for the MCS.

Socioeconomic factors, health-related practices, visual and hearing capacity, and psychosocial support Data on health-related practices, psychosocial support, and socioeconomic factors (including age, gender, education, marital status and money use) were collected through self-administered questionnaires. Visual and hearing capacities were categorized as good, general, and bad/blind or $\mathrm{bad} /$ deaf. Health-related practices, such as tobacco use and alcohol consumption, were categorized as never and former/current. Regular exercise was categorized as "yes" or "no". Psychosocial support was assessed using two statements: "Someone is listening when you talk" and "You see relatives/friends when you want".

Frailty status and chronic illness and problems We adopted the definition of frailty proposed by Fried et al. [11], consisting of five components: unintended weight loss, weakness, poor endurance and energy, slowness, and low physical activity level. In this study, unintended weight loss was defined as weight loss ${ }^{3} 3 \mathrm{~kg}$ over the course of the previous year; weakness was defined as grip strength in the lowest quintile at baseline, based on the subgroups of gender and body mass index. Poor endurance and energy were evaluated by self-reported exhaustion and by two questions from the Center for Epidemiological Studies-Depression scale [12]. Slowness was measured for each gender and height subgroup and was defined as the slowest quintile to walk a distance of 15 feet and was divided into gender and height subgroups 
[11]. Low physical activity level was measured for each gender and was defined as the lowest quintile of kilocalories spent every week (using weighted scores), based on responses from each participant. Subjects exhibiting none of the above components were considered robust; those with one or two components were considered pre-frail; and those with more than two components were considered frail.

Self-reported personal medical histories-including diabetes mellitus, hypertension, heart disease, stroke, arthritis, hyperlipidemia, gout, hyperuricemia, cataract, and fall histories-were collected. Pain problems and sleep disorders were also collected as "yes" or "no" binary responses.

\section{Statistical analysis}

Continuous variables were reported as mean \pm standard deviation (SD), and categorical variables were reported as numbers and percentages. Student's $t$-test was used to compare the eight dimensions and the two component summaries of SF-36 among elders who were and were not aging successfully. Univariate logistic regression was used to explore the associations of sociodemographic factors, psychosocial support, visual and hearing capacities, health-related practices, and chronic health problems with successful aging. Variables found to be statistically significant by univariate logistic regression analysis were selected to further evaluate their relative contributions using four multivariate logistic regression models. First, the sociodemographic and psychosocial support factors were evaluated by multivariate logistic regression. Health-related practices and visual and hearing capacities were then added to the second model; chronic illness and fall history were then added to the third model; and pain, sleep disorders, and frailty were finally added to the fourth model. All calculations were repeated for sensitivity analysis. The cutoff point of both the PCS and the MCS for defining successful aging was changed from the highest tertile to the seventieth percentile and the fourth quartile. All reported p-values were those of two-sided tests; significance was defined as $\mathrm{p}<0.05$. All analyses were performed using SAS version 9.2 statistical software (SAS Institute Inc., Cary, NC, USA).

\section{Results}

Of the 903 elders (mean age, 73.90 years) enrolled in this study, $10.4 \%$ were identified as successful agers. Successfully aging elders had significantly higher scores in eight SF-36 dimensions than those who were not successfully aging; they also had the most favorable health status (with scores of 100) in the RP, SF, and RE variables (Table 1).
Table 1 Comparison of eight dimensions and two component summaries of SF-36 between successfully aging and not successfully aging elders

\begin{tabular}{|c|c|c|c|c|c|}
\hline & \multicolumn{2}{|c|}{$\begin{array}{l}\text { Not successfully aging } \\
\qquad(\mathrm{n}=809)\end{array}$} & \multicolumn{2}{|c|}{$\begin{array}{l}\text { Successfully aging } \\
\qquad(\mathrm{n}=94)\end{array}$} & \multirow[b]{2}{*}{ p value } \\
\hline & Mean & SD & Mean & SD & \\
\hline $\mathrm{PF}$ & 80.99 & 20.14 & 96.17 & 4.49 & $<0.001$ \\
\hline $\mathrm{RP}$ & 83.87 & 34.17 & 100.00 & 0.00 & $<0.001$ \\
\hline $\mathrm{BP}$ & 78.57 & 21.31 & 98.45 & 5.72 & $<0.001$ \\
\hline $\mathrm{GH}$ & 59.41 & 19.60 & 84.85 & 10.05 & $<0.001$ \\
\hline VT & 70.90 & 18.55 & 93.99 & 6.54 & $<0.001$ \\
\hline SF & 91.12 & 16.27 & 100.00 & 0.00 & $<0.001$ \\
\hline $\mathrm{RE}$ & 90.40 & 27.80 & 100.00 & 0.00 & $<0.001$ \\
\hline $\mathrm{MH}$ & 79.18 & 16.18 & 97.36 & 3.29 & $<0.001$ \\
\hline PCS & 47.50 & 8.07 & 55.32 & 1.41 & $<0.001$ \\
\hline MCS & 54.61 & 7.68 & 61.31 & 1.11 & $<0.001$ \\
\hline
\end{tabular}

Physical functioning (PF), Role physical (RP), Bodily pain (BP), General health $(\mathrm{GH})$, Vitality (VT), Social functioning (SF), Role emotional (RE), Mental health $(\mathrm{MH})$, Physical component summary (PCS), and Mental component summary (MCS).

Older elders, females, and elders without enough or with just enough money for personal use had a lower prevalence of successful aging. The unadjusted analysis showed a higher prevalence of successful aging among elders with $\geq 7$ years of education, with general or good visual capacity, with good hearing capacity, who regularly exercised, and who were able to see relatives and friends whenever they wished (Table 2).

Among the associations with chronic health problems, increased odds of successful aging were found in non-frail elders and in those without hypertension, heart disease, hyperuricemia, arthritis, cataracts, fall histories, pain problems, or sleep disorders (Table 3).

Nested logistic regression analysis was used to further examine the interrelatedness of factors significantly associated with successful aging. Among socioeconomic and psychosocial support factors, the odds of successful aging were significantly lower for the very elderly and for those with insufficient income. After accounting for the effects of visual capacity, hearing capacity, and exercise habits on successful aging, the significance of age remained unchanged while the strength of the financial resources association diminished. Meanwhile, we observed increased odds of successful aging for elders with general or good visual capacity and for those who exercised regularly. After chronic illness and history of falling were added into the regression model, successfulness of aging was statistically associated with an age range of 71-75 years; regular exercise; and the absence of heart disease, arthritis, and fall histories.

The associations of regular exercise and chronic diseases with successful aging disappeared, however, after adding 
Table 2 Prevalence and odds ratio of successful aging defined by health-related quality of life among socio-demographic factors, visual and hearing capacity, and health-related practices

\begin{tabular}{|c|c|c|c|c|c|}
\hline \multirow[t]{2}{*}{ Variable } & \multirow[t]{2}{*}{ Total $\mathbf{n}$} & \multicolumn{2}{|c|}{ Successful aging } & \multirow[t]{2}{*}{ OR } & \multirow[t]{2}{*}{$95 \% \mathrm{Cl}$} \\
\hline & & $\mathrm{n}$ & $\%$ & & \\
\hline Total & 903 & 94 & 10.4 & - & - \\
\hline \multicolumn{6}{|c|}{ Socio-demographic factors } \\
\hline \multicolumn{6}{|l|}{ Age (years) } \\
\hline$\leq 70$ & 339 & 54 & 15.93 & 1.00 & \\
\hline $71-75$ & 226 & 14 & 6.19 & 0.35 & $(0.19,0.64)$ \\
\hline$>75$ & 338 & 26 & 7.69 & 0.44 & $(0.27,0.72)$ \\
\hline \multicolumn{6}{|l|}{ Gender } \\
\hline Men & 477 & 61 & 12.79 & 1.00 & \\
\hline Women & 426 & 33 & 7.75 & 0.57 & $(0.37,0.89)$ \\
\hline \multicolumn{6}{|l|}{ Education } \\
\hline Illiterate & 103 & 3 & 2.91 & 1.00 & \\
\hline$\leq 6$ years & 229 & 16 & 6.99 & 2.50 & $(0.71,8.79)$ \\
\hline $7-12$ years & 308 & 42 & 13.64 & 5.26 & $(1.60,17.36)$ \\
\hline$\geq 13$ years & 240 & 33 & 13.75 & 5.31 & $(1.59,17.75)$ \\
\hline \multicolumn{6}{|l|}{ Marital status } \\
\hline Current & 644 & 74 & 11.49 & 1.00 & \\
\hline Others & 256 & 20 & 7.81 & 0.65 & $(0.39,1.09)$ \\
\hline \multicolumn{6}{|l|}{ Money use } \\
\hline Enough & 210 & 32 & 15.24 & 1.00 & \\
\hline Just enough & 578 & 57 & 9.86 & 0.61 & $(0.38,0.97)$ \\
\hline Not enough & 111 & 5 & 4.50 & 0.26 & $(0.10,0.69)$ \\
\hline \multicolumn{6}{|c|}{ Visual and hearing capacity } \\
\hline \multicolumn{6}{|l|}{ Visual capacity } \\
\hline Bad/blind & 245 & 10 & 4.08 & 1.00 & \\
\hline General & 410 & 42 & 10.24 & 2.68 & $(1.32,5.45)$ \\
\hline Good & 245 & 42 & 17.14 & 4.86 & $(2.38,9.94)$ \\
\hline \multicolumn{6}{|l|}{ Hearing capacity } \\
\hline $\mathrm{Bad} /$ deaf & 152 & 9 & 5.92 & 1.00 & \\
\hline General & 308 & 17 & 5.52 & 0.93 & $(0.40,2.13)$ \\
\hline Good & 443 & 68 & 15.35 & 2.88 & $(1.40,5.93)$ \\
\hline \multicolumn{6}{|c|}{ Health-related practices } \\
\hline \multicolumn{6}{|l|}{ Regular exercise } \\
\hline No & 217 & 11 & 5.07 & 1.00 & \\
\hline Yes & 683 & 83 & 12.15 & 2.59 & $(1.35,4.96)$ \\
\hline \multicolumn{6}{|l|}{ Smoking } \\
\hline No & 711 & 74 & 10.41 & 1.00 & \\
\hline Current & 82 & 12 & 14.63 & 1.48 & $(0.76,2.85)$ \\
\hline Former & 110 & 8 & 7.27 & 0.68 & $(0.32,1.44)$ \\
\hline \multicolumn{6}{|l|}{ Drinking } \\
\hline No & 727 & 70 & 9.63 & 1.00 & \\
\hline Current & 121 & 17 & 14.05 & 1.53 & $(0.87,2.71)$ \\
\hline Former & 55 & 7 & 12.73 & 1.37 & $(0.60,3.14)$ \\
\hline
\end{tabular}


Table 2 Prevalence and odds ratio of successful aging defined by health-related quality of life among socio-demographic factors, visual and hearing capacity, and health-related practices (Continued)

\begin{tabular}{|c|c|c|c|c|c|}
\hline Psycho & & & & & \\
\hline Someo & & & & & \\
\hline No & 59 & 3 & 5.08 & 1.00 & \\
\hline Yes & 842 & 91 & 10.81 & 2.26 & $(0.69,7.37)$ \\
\hline You see & & & & & \\
\hline No & 114 & 3 & 2.63 & 1.00 & \\
\hline Yes & 786 & 90 & 11.45 & 4.78 & $(1.49,15.38)$ \\
\hline
\end{tabular}

the factors of pain, sleep disorders and frailty in the fourth model. In the final model, the odds of successful aging decreased in elders aged $71-75$ years relative to those $\leq 70$ years (adjusted odds ratio [OR]: 0.27; $95 \%$ confidence interval [CI]: $0.13-0.58)$ and in those in pre-frail states. An increase in the odds of successful aging was observed in elders who were able to visit relatives and friends whenever they wished (OR: 3.86; 95\% CI: 1.09-13.61) and in those without a history of falling (OR: 4.95; 95\% CI: 1.7913.74), pain (OR: 4.04; 95\% CI: 2.18-7.50), or sleep disorders (OR: 2.36; 95\% CI: 1.30-4.27) (Table 4).

The sensitivity analysis results showed that age, fall history, and pain were still significantly associated with successful aging when using the highest cutoff value at the seventieth percentile for both the PCS and the MCS. Successful aging associations with sleep disorders and visiting relatives and friends were strong but insignificant. Using the highest quartile as a cut-off value, only fall history and pain were significantly associated with successful aging. All elders who were frail were found to be unsuccessfully aging; however, the factor of frailty could not be added to the final multivariate model due to problems with statistical convergence.

\section{Discussion}

The prevalence of successful aging, as was defined using SF-36, was $10.4 \%$ in community-dwelling elders in a metropolitan population of Taiwan. Elders with chronic diseases or other health-related problems had a lower prevalence of successful aging compared with those without such health issues. All elderly people who had had a stroke, for example, were considered to be unsuccessfully aging. Elders more likely to be successfully aging, however, were $\leq 70$ years old; were are able to visit relatives or friends whenever they wished; and had no history of falling, pain, or sleep disorders.

We adopted the five components of frailty defined by Fried et al. [11] that included objective, performance-based measures. A previous study had reported that frailty in elders is an important clinical state that is distinct from normal aging and a strong predictor for disability [11]. In this study, frailty was found to be an independent determinant of successful aging. Among frail elders, only one (0.93\%) was found to be successfully aging; and even after PCS and MCS cutoff values were increased from tertile to a higher percentile, no other frail elders were found to be successfully aging. These results indicated that gauging successful aging using SF-36 is not only easy but also reflects actual health conditions. A noteworthy additional study by Theou et al., however, reported that frailty in elders can be reversed by structured exercise training [13].

The prevalence of successful aging among previous community-based studies ranges from $0.4 \%$ to $95 \%$ based on various definitions [5,6,12,14-20]. In general, those studies using a single-item, self-rating scale reported a higher and more variable prevalence of successful aging, ranging from $50.3 \%$ to $90.2 \%[6,15,18]$. The focus of many studies on successful aging has shifted from disease status and functional decline to multidimensional health status, which encompasses physical, functional, psychological, and social health [21]. Early published reports defined successful aging using only one or two dimensions of health, such as the absence of chronic diseases, longer longevity, independent physical functioning, social life engagement, and mental health $[14,16,17,19]$. However, more recent studies have focused on the concept that successful aging is more multifaceted and complex [5,7]. Studies using the absence of major disease as one of the domains to define successful aging in elders reported a lower prevalence of successful aging $[15,18,20]$ compared with those not using this domain $[5,7,12,15]$. To obtain a comparable prevalence of successful aging among elders and to explore the associated determinants, there is a need for a simple, standardized and multidimensional tool to be used across studies. In a study conducted in Hong Kong, higher PCS and MCS scores in SF-36 reflected better overall physical, functional, psychological, and social health in Chinese elders [22]. Consequently, higher PCS and MCS scores in SF-36 among elders were used to define successful aging in this study.

Age is a commonly identified determinant of successful aging. Consistent with the results reported in previous studies [5,23,24], younger age was one determinant of successful aging among elders in this study. We also found 
Table 3 Prevalence and odds ratios of successful aging defined by health-related quality of life among chronic illness, problems, and frailty status

\begin{tabular}{|c|c|c|c|c|c|}
\hline \multirow[t]{2}{*}{ Variable } & \multirow[t]{2}{*}{ Total $n$} & \multicolumn{2}{|c|}{ Successful aging } & \multirow[t]{2}{*}{ OR } & \multirow[t]{2}{*}{$95 \% \mathrm{Cl}$} \\
\hline & & $\mathrm{n}$ & $\%$ & & \\
\hline \multicolumn{6}{|l|}{ Hypertension } \\
\hline Yes & 474 & 37 & 7.81 & 1.00 & \\
\hline No & 420 & 57 & 13.57 & 1.85 & $(1.2,2.87)$ \\
\hline \multicolumn{6}{|c|}{ Diabetes mellitus } \\
\hline Yes & 154 & 12 & 7.79 & 1.00 & \\
\hline No & 740 & 81 & 10.95 & 1.45 & $(0.77,2.74)$ \\
\hline \multicolumn{6}{|l|}{ Heart disease } \\
\hline Yes & 264 & 13 & 4.92 & 1.00 & \\
\hline No & 639 & 81 & 12.68 & 2.80 & $(1.53,5.13)$ \\
\hline \multicolumn{6}{|c|}{ Hyperlipidemia } \\
\hline Yes & 226 & 21 & 9.29 & 1.00 & \\
\hline No & 662 & 73 & 11.03 & 1.21 & $(0.73,2.02)$ \\
\hline \multicolumn{6}{|l|}{ Gout } \\
\hline Yes & 110 & 7 & 6.36 & 1.00 & \\
\hline No & 781 & 87 & 11.14 & 1.84 & $(0.83,4.09)$ \\
\hline \multicolumn{6}{|c|}{ Hyperuricemia } \\
\hline Yes & 105 & 4 & 3.81 & 1.00 & \\
\hline No & 786 & 89 & 11.32 & 3.22 & $(1.16,8.97)$ \\
\hline \multicolumn{6}{|l|}{ Arthritis } \\
\hline Yes & 178 & 7 & 3.93 & 1.00 & \\
\hline No & 691 & 82 & 11.87 & 3.29 & $(1.49,7.25)$ \\
\hline \multicolumn{6}{|l|}{ Stroke } \\
\hline Yes & 48 & 0 & 0.00 & 1.00 & \\
\hline No & 837 & 94 & 11.23 & - & - \\
\hline \multicolumn{6}{|l|}{ Cataract } \\
\hline Yes & 421 & 32 & 7.60 & 1.00 & \\
\hline No & 477 & 62 & 13.00 & 1.82 & $(1.16,2.84)$ \\
\hline \multicolumn{6}{|l|}{ Fall history } \\
\hline Yes & 702 & 87 & 12.39 & 1.00 & \\
\hline No & 188 & 7 & 3.72 & 3.65 & $(1.66,8.04)$ \\
\hline \multicolumn{6}{|c|}{ Pain problem } \\
\hline Yes & 471 & 19 & 4.03 & 1.00 & \\
\hline No & 401 & 74 & 18.45 & 5.38 & $(3.19,9.09)$ \\
\hline \multicolumn{6}{|c|}{ Sleep disorder } \\
\hline Yes & 394 & 22 & 5.58 & 1.00 & \\
\hline No & 497 & 71 & 14.29 & 2.82 & $(1.71,4.64)$ \\
\hline \multicolumn{6}{|l|}{ Frailty } \\
\hline Non-frail & 368 & 62 & 16.85 & 1.00 & \\
\hline Pre-fail & 428 & 31 & 7.24 & 0.39 & $(0.24,0.61)$ \\
\hline Frail & 107 & 1 & 0.93 & 0.05 & $(0.01,0.34)$ \\
\hline
\end{tabular}

OR: odds ratio; $95 \% \mathrm{Cl}$ : $95 \%$ confidence interval; Results in bold are significant at $\mathrm{p}<0.05$. that the ability to see relatives and friends at will (as a variable related to social support) was an independent determinant for successful aging among the elderly. Pruchno et al. [23] reported that unsuccessfully aging elders have less social support compared with successful agers. Our findings on the associations among sleep disorders, fall histories, and successful aging were similar to those in prior research [25]. Elderly persons with sleep disorders were at a higher risk of unsuccessfully aging compared with those without sleep disorders. This finding provides evidence supporting a previous study by Andrews et al. [25] that defined the concept of high functioning and found that elders without sufficient sleep were less likely to be in the high functioning category. In our findings, a history of falling was associated with a lower likelihood of successful aging, as those with such a history tend to restrict outdoor activity out of a fear of falling [26]. In general, the fear of falling has tended to impede elderly participation in healthy activities and leads to decreased mobility, resulting in diminished quality of life $[27,28]$.

Previous studies have reported that chronic diseasessuch as arthritis, diabetes, stroke, and hypertension-were all associated with successful aging. [5,16] We found that these diseases were not independent risk factors of unsuccessful aging because their effects were explained by falls, frailty, pain, and sleep problems. Among these chronic diseases, stroke had a major impact on successful aging; all elders who had a history of stroke in this study were found to be unsuccessfully aging. Strokes were not, however, added to the final multivariate model due to problems with statistical convergence. We observed lower physical component scores in elders with stroke histories compared with those without stroke histories; no significant differences were observed in mental component scores. Consistent with the findings of Okonkwo et al. [29], the difference in PCS scores between subjects with and without a stroke history in this study was approximately twofold that in MCS scores. In contrast to our findings on stroke effects, Haley et al. [30] indicated that an incident of stroke has a negative impact in both mental and physical health over a three-year period. One possible explanation for these different findings is that the elders in our present study had already coped with their conditions, allowing for better mental health.

In present study, we used Cohen's $\mathrm{d}$ in the chi-square value formula $\left(\mathrm{d}=\sqrt{\left(4 x^{2}\right) /\left(N-x^{2}\right)}\right.$, where $\mathrm{N}$ is total sample size) [31] to calculate the effect size of significant factors. Our results indicated a mid-size effect of both pain $(d=0.47)$ and frailty $(d=0.38)$. The effect sizes of other factors (including age, seeing relatives and friends at will, fall histories, and sleep disorders) were small, between 0.2 and 0.3 . The two determinants of pain problems 
Table 4 Nested logistic regression analysis of successful aging defined by health-related quality of life

\begin{tabular}{|c|c|c|c|c|c|c|c|c|c|c|c|c|c|}
\hline \multirow{3}{*}{$\frac{\text { Variable }}{\text { Age (years) }}$} & \multirow{3}{*}{$\begin{array}{l}\text { Effect } \\
71-75 \text { vs } \leq 70\end{array}$} & \multicolumn{3}{|c|}{ Model I } & \multicolumn{3}{|c|}{ Model II } & \multicolumn{3}{|c|}{ Model III } & \multicolumn{3}{|c|}{ Model IV } \\
\hline & & \multirow{2}{*}{$\begin{array}{l}\text { OR } \\
0.36\end{array}$} & \multicolumn{2}{|c|}{$95 \% \mathrm{Cl}$} & \multirow{2}{*}{$\begin{array}{l}\mathrm{OR} \\
0.36\end{array}$} & \multicolumn{2}{|c|}{$95 \% \mathrm{Cl}$} & \multirow{2}{*}{$\begin{array}{l}\mathrm{OR} \\
0.34\end{array}$} & \multicolumn{2}{|c|}{$95 \% \mathrm{Cl}$} & \multirow{2}{*}{$\begin{array}{l}\text { OR } \\
0.27\end{array}$} & \multicolumn{2}{|c|}{$95 \% \mathrm{Cl}$} \\
\hline & & & 0.18 & 0.69 & & 0.18 & 0.70 & & 0.17 & 0.70 & & 0.13 & 0.58 \\
\hline & $>75$ vs $\leq 70$ & 0.38 & 0.22 & 0.67 & 0.41 & 0.23 & 0.74 & 0.53 & 0.28 & 1.02 & 0.60 & 0.30 & 1.21 \\
\hline Gender & Women vs Men & 0.64 & 0.39 & 1.08 & 0.79 & 0.46 & 1.36 & 0.88 & 0.50 & 1.56 & 1.08 & 0.58 & 2.00 \\
\hline \multirow[t]{3}{*}{ Education } & $\leq 6$ years vs Illiterate & 1.49 & 0.41 & 5.41 & 1.07 & 0.28 & 4.03 & 0.99 & 0.26 & 3.88 & 1.03 & 0.25 & 4.27 \\
\hline & $7-12$ years vs Illiterate & 2.87 & 0.84 & 9.79 & 1.91 & 0.54 & 6.75 & 1.93 & 0.53 & 7.03 & 1.61 & 0.42 & 6.22 \\
\hline & $\geq 13$ years vs Illiterate & 2.86 & 0.81 & 10.11 & 2.18 & 0.60 & 7.99 & 2.18 & 0.58 & 8.28 & 1.87 & 0.46 & 7.63 \\
\hline \multirow[t]{2}{*}{ Money use } & Just enough vs Enough & 0.76 & 0.45 & 1.27 & 0.85 & 0.50 & 1.45 & 0.90 & 0.51 & 1.60 & 1.04 & 0.56 & 1.93 \\
\hline & Not enough vs Enough & 0.35 & 0.12 & 0.97 & 0.40 & 0.14 & 1.14 & 0.39 & 0.13 & 1.16 & 0.54 & 0.17 & 1.75 \\
\hline $\begin{array}{l}\text { You see relatives/friends when } \\
\text { you want }\end{array}$ & Yes vs No & 3.08 & 0.93 & 10.22 & 2.77 & 0.82 & 9.36 & 3.45 & 1.00 & 11.89 & 3.86 & 1.09 & 13.61 \\
\hline \multirow[t]{2}{*}{ Visual capacity } & General vs Bad/Blind & & & & 2.32 & 1.04 & 5.18 & 2.07 & 0.90 & 4.73 & 1.36 & 0.57 & 3.27 \\
\hline & Good vs Bad/Blind & & & & 2.15 & 1.01 & 4.60 & 2.06 & 0.94 & 4.54 & 1.67 & 0.74 & 3.79 \\
\hline \multirow[t]{2}{*}{ Hearing capacity } & General vs Bad/Deaf & & & & 2.00 & 0.84 & 4.73 & 1.57 & 0.64 & 3.81 & 1.78 & 0.70 & 4.54 \\
\hline & Good vs Bad/Deaf & & & & 0.66 & 0.25 & 1.77 & 0.53 & 0.19 & 1.46 & 0.48 & 0.17 & 1.36 \\
\hline Regular exercise & Yes vs No & & & & 2.71 & 1.25 & 5.87 & 2.73 & 1.24 & 6.02 & 1.53 & 0.61 & 3.79 \\
\hline Hypertension & No vs Yes & & & & & & & 1.42 & 0.84 & 2.42 & 1.38 & 0.78 & 2.42 \\
\hline Heart disease & No vs Yes & & & & & & & 2.07 & 1.01 & 4.26 & 2.06 & 0.96 & 4.42 \\
\hline Hyperuricemia & No vs Yes & & & & & & & 3.16 & 0.92 & 10.87 & 3.19 & 0.89 & 11.49 \\
\hline Arthritis & No vs Yes & & & & & & & 2.47 & 1.06 & 5.80 & 1.82 & 0.74 & 4.45 \\
\hline Cataract & No vs Yes & & & & & & & 1.05 & 0.59 & 1.86 & 1.07 & 0.59 & 1.97 \\
\hline Fall history & No vs Yes & & & & & & & 4.08 & 1.55 & 10.72 & 4.95 & 1.79 & 13.74 \\
\hline Pain problem & No vs Yes & & & & & & & & & & 4.04 & 2.18 & 7.50 \\
\hline Sleep disorder & No vs Yes & & & & & & & & & & 2.36 & 1.30 & 4.27 \\
\hline \multirow[t]{2}{*}{ Frailty } & Pre-fail vs Non-frail & & & & & & & & & & 0.45 & 0.24 & 0.84 \\
\hline & Frail vs Non-frail & & & & & & & & & & 0.14 & 0.02 & 1.13 \\
\hline Adjusted McFadden's $R^{2}$ & & $9.1 \%$ & & & $16.0 \%$ & & & $23.4 \%$ & & & $32.3 \%$ & & \\
\hline Likelihood ratio test $^{\dagger}$ & & - & & & $p<0.001$ & & & $p<0.001$ & & & $p<0.001$ & & \\
\hline
\end{tabular}

OR: odds ratio; $95 \% \mathrm{Cl}$ : $95 \%$ confidence interval; Results in bold are significant at $\mathrm{p}<0.05$.

${ }^{\dagger}$ : The current model compared with prior model.

and frailty were found to have greater relative association with successful aging.

The present study has certain limitations that should be taken into account when interpreting the results. First, owing to the nature of the cross-sectional study, we cannot explore the possible causal relationships between the health conditions considered in this study and successful aging. Second, the findings of our work are not generalizable to rural elders because this study sample was a group of metropolitan elders. Finally, the prevalence of successful aging in urban elders may have been overestimated due to the exclusion of elders who were diagnosed with dementia, had cognitive impairment, and were unable complete the SF-36 questionnaire. Our study's elders reflected the general global measures of physical and mental dysfunction, rather than those of specific disabilities or impairments [32].

\section{Conclusions}

The following conclusions can be drawn from the present study: the higher proportion of successful aging in elders was found among those who were relatively younger, had social support, not frail, and had no pain, sleep impairment, and fall history. These findings revealed the importance of considering suitable intervention to improve the frailty, pain, and sleep problems among the elders. However, the causal relationships between these factors and successful aging will require further investigations.

\section{Competing interests}

The authors declare that they have no competing interests.

\section{Authors' contributions}

$C C L$ and $T C L$ designed the study. CIL drafted the manuscript. $C C L, C H L, W Y L$, CSL, CKC, and NHM carried out the study, participated in coordination and evaluation of data. YDL contributed to the study with his knowledge on field 
study. CIL and TCL carried out the data organization and performed the statistical analysis. All authors read and approved the final manuscript.

\section{Acknowledgments}

This research was supported by the Taiwan National Health Research Institutes Grant (NHRI-EX99-9838PI, NHRI-EX100-9838PI, NHRI-EX101-9838PI), Taiwan Ministry of Health and Welfare Clinical Trial and Research Center of Excellence (MOHW103-TDU-B-212-113002), and China Medical University Hospital (DMR-100-075).

\section{Author details}

'Department of Medical Research, China Medical University Hospital, Taichung, Taiwan. ${ }^{2}$ School of Medicine, College of Medicine, China Medical University, Taichung, Taiwan. ${ }^{3}$ Department of Family Medicine, China Medical University Hospital, Taichung, Taiwan. ${ }^{4}$ Department of Physical Medicine and Rehabilitation, China Medical University Hospital, Taichung, Taiwan. ${ }^{5}$ Department of Psychiatry, Medical College, National Cheng-Kung University, Tainan, Taiwan. ${ }^{6}$ Medical Division, Sanofi Taiwan Co., Ltd, Taipei, Taiwan. ${ }^{7}$ Graduate Institute of Biostatistics, College of Management, China Medical University, Taichung, Taiwan. ${ }^{8}$ Department of Healthcare Administration, College of Medical and Health Science, Asia University, Taichung, Taiwan. ${ }^{9}$ China Medical University and Hospital, 2 Yude Road, Taichung 40421, Taiwan.

Received: 8 August 2013 Accepted: 18 September 2014 Published: 28 September 2014

\section{References}

1. Kinsella K, He W: An Aging World: 2008. Washington, DC: US Government Printing Office; 2009. US Census Bureau. In International Population Reports, PS95/09-1.

2. Molton IR, Jensen MP: Aging and disability: biopsychosocial perspectives. Phys Med Rehabil Clin N Am 2010, 21(2):253-265.

3. Finlayson ML, Peterson EW: Falls, aging, and disability. Phys Med Rehabil Clin N Am 2010, 21(2):357-373.

4. Depp CA, Jeste DV: Definitions and predictors of successful aging: a comprehensive review of larger quantitative studies. Am J Geriatr Psychiatry 2006, 14(1):6-20.

5. Ng TP, Broekman BF, Niti M, Gwee X, Kua EH: Determinants of successful aging using a multidimensional definition among Chinese elderly in Singapore. Am J Geriatr Psychiatry 2009, 17(5):407-416.

6. Pruchno RA, Wilson-Genderson M, Cartwright F: A two-factor model of successful aging. J Gerontol B Psychol Sci Soc Sci 2010, 65(6):671-679.

7. Hank K: How "successful" do older Europeans age? Findings From SHARE. J Gerontol B Psychol Sci Soc Sci 2011, 66(2):230-236.

8. Ware JE Jr, Gandek B: Overview of the SF-36 health survey and the international quality of life assessment (IQOLA) Project. J Clin Epidemiol 1998, 51(11):903-912.

9. World Health Organization: Constitution of the World Health Organization. Geneva, Switzerland: WHO Basic Documents; 1948.

10. Lin CC, Li Cl, Chang CK, Liu CS, Lin CH, Meng NH, Lee YD, Chen FN, Li TC: Reduced health-related quality of life in elders with frailty: a crosssectional study of community-dwelling elders in Taiwan. PLoS One 2011, 6(7):e21841.

11. Fried LP, Tangen CM, Walston J, Newman AB, Hirsch C, Gottdiener J, Seeman T, Tracy R, Kop WJ, Burke G: Frailty in older adults: evidence for a phenotype. J Gerontol A Biol Sci Med Sci 2001, 56(3):M146-M157.

12. Almeida OP, Norman P, Hankey G, Jamrozik K, Flicker L: Successful mental health aging: results from a longitudinal study of older Australian men. Am J Geriatr Psychiatry 2006, 14(1):27-35.

13. Theou O, Stathokostas L, Roland KP, Jakobi JM, Patterson C, Vandervoort AA, Jones GR: The effectiveness of exercise interventions for the management of frailty: a systematic review. J Aging Res 2011, 2011:569194.

14. Garfein AJ, Herzog AR: Robust aging among the young-old, old-old, and oldest-old. J Gerontol B Psychol Sci Soc Sci 1995, 50(2):S77-S87.

15. Montross LP, Depp C, Daly J, Reichstadt J, Golshan S, Moore D, Sitzer D, Jeste DV: Correlates of self-rated successful aging among communitydwelling older adults. Am J Geriatr Psychiatry 2006, 14(1):43-51.

16. von Faber M, Bootsma-van der Wiel A, van Exel E, Gussekloo J, Lagaay AM, van Dongen E, Knook DL, van der Geest S, Westendorp RG: Successful aging in the oldest old: who can be characterized as successfully aged? Arch Intern Med 2001, 161(22):2694-2700.

17. Strawbridge WJ, Cohen RD, Shema SJ, Kaplan GA: Successful aging: predictors and associated activities. Am J Epidemiol 1996, 144(2):135-141.

18. Strawbridge WJ, Wallhagen MI, Cohen RD: Successful aging and wellbeing: self-rated compared with Rowe and Kahn. Gerontologist 2002, 42(6):727-733

19. Burke GL, Arnold AM, Bild DE, Cushman M, Fried LP, Newman A, Nunn C Robbins J: Factors associated with healthy aging: the cardiovascular health study. J Am Geriatr Soc 2001, 49(3):254-262.

20. McLaughlin SJ, Connell CM, Heeringa SG, Li LW, Roberts JS: Successful aging in the United States: prevalence estimates from a national sample of older adults. J Gerontol B Psychol Sci Soc Sci 2010, 65B(2):216-226.

21. Phelan EA, Anderson LA, LaCroix AZ, Larson EB: Older adults' views of "successful aging"-how do they compare with researchers' definitions? J Am Geriatr Soc 2004, 52(2):211-216.

22. Lam CL, Tse EY, Gandek B, Fong DY: The SF-36 summary scales were valid, reliable, and equivalent in a Chinese population. J Clin Epidemiol 2005, 58(8):815-822

23. Pruchno RA, Wilson-Genderson M, Rose M, Cartwright F: Successful aging: early influences and contemporary characteristics. Gerontologist 2010, 50(6):821-833.

24. Newman AB, Arnold AM, Naydeck BL, Fried LP, Burke GL, Enright P, Gottdiener J, Hirsch C, O'Leary D, Tracy R: "Successful aging": effect of subclinical cardiovascular disease. Arch Intern Med 2003, 163(19):2315-2322.

25. Andrews G, Clark M, Luszcz M: Successful aging in the Australian longitudinal study of aging: applying the MacArthur model crossnationally. J Soc Issues 2002, 58(4):749-765.

26. Fletcher PC, Guthrie DM, Berg K, Hirdes JP: Risk factors for restriction in activity associated with fear of falling among seniors within the community. J Patient Saf 2010, 6(3):187-191.

27. Vellas BJ, Wayne SJ, Romero LJ, Baumgartner RN, Garry PJ: Fear of falling and restriction of mobility in elderly fallers. Age Ageing 1997, 26(3):189-193.

28. Brouwer B, Musselman K, Culham E: Physical function and health status among seniors with and without a fear of falling. Gerontology 2004, 50(3):135-141.

29. Okonkwo OC, Roth DL, Pulley L, Howard G: Confirmatory factor analysis of the validity of the SF-12 for persons with and without a history of stroke. Qual Life Res 2010, 19(9):1323-1331.

30. Haley WE, Roth DL, Kissela B, Perkins M, Howard G: Quality of life after stroke: a prospective longitudinal study. Qual Life Res 2011, 20(6):799-806.

31. Dunst CJ, Hamby DW, Trivette CM: Guidelines for calculating effect sizes for practice-based research syntheses. Centerscope 2004, 3(1):1-10.

32. Parker SG, Bechinger-English D, Jagger C, Spiers N, Lindesay J: Factors affecting completion of the SF-36 in older people. Age Ageing 2006, 35(4):376-381.

doi:10.1186/1471-2458-14-1013

Cite this article as: Li et al.: Successful aging defined by health-related quality of life and its determinants in community-dwelling elders. BMC Public Health 2014 14:1013.

\section{Submit your next manuscript to BioMed Central and take full advantage of:}

- Convenient online submission

- Thorough peer review

- No space constraints or color figure charges

- Immediate publication on acceptance

- Inclusion in PubMed, CAS, Scopus and Google Scholar

- Research which is freely available for redistribution 